Bayron Velásquez, La Organa y la escuela de guerrilla de Chaihuín (1968-1970): Leninización y guevarización del socialismo chileno, Izquierdas, 49, abril 2020:412-431

\title{
La Organa y la escuela de guerrilla de Chaihuín (1968-1970): Leninización y guevarización del socialismo chileno
}

The Organa and the guerrilla school in Chaihuín (1968-1970): Leninization and guevarization of the Chilean socialism

Bayron Velásquez Paredes*

Resumen: En mayo de 1970 fue descubierta y desarticulada una escuela de guerrilla en Chaihuín (localidad costera cercana a la Provincia de Valdivia), la cual fue sostenida por un grupo interno del Partido Socialista de Chile (PS) denominado la Organa. En el presente artículo buscaremos, en primer lugar, reconstruir la experiencia de la Organa y la escuela de guerrilla Chaihuín, y en segundo, comprender que este episodio es parte de los procesos de leninización y guevarización experimentados por el PS desde fines de 1950.

Palabras claves: Partido Socialista de Chile, leninización, guevarización, escuela de guerrilla.

Abstract: In may 1970 a guerrilla school was discovered and disarmament in Chaihuín (a coastal town near the province of Valdivia), which was sustained by an intern group of the Socialist Party of Chile named Organa. First, this research seeks to reconstruct the Organa and the Chaihuín guerrilla school experience. Secondly, to comprehend that this episode is part of the leninization and guevarization processes experienced by the Socialist Party of Chile since end of 1950.

Key words: Socialist Party of Chile, leninization, guevarization, guerrilla school.

Recibido: 14 diciembre 2018 Aceptado: 27 febrero 2019

\section{Introducción}

En mayo de 1970, a tan solo meses de la elección presidencial donde resultó electo Salvador Allende, fue descubierta una escuela de instrucción guerrillera en el sur de Chile, en los alrededores de un pequeño caserío llamado Chaihuín ${ }^{2}$. Esta comenzó a ser levantada en octubre de 1969 e inició sus actividades en enero del 1970, alcanzando a pasar por ella dos grupos de militantes que recibieron instrucción guerrillera antes de su desarticulación. La experiencia fue sostenida por un grupo interno del PS conocido como la Organa, el cual nació en 1968 con el objetivo de preparar las condiciones para un posible enfrentamiento armado.

El descubrimiento de esta escuela provocó un gran revuelo social, lo que era esperable si consideramos que, a ojos de la opinión pública, era contradictorio que uno de los partidos que levantaba una candidatura presidencial fuera sorprendido desarrollando actividades de formación guerrillera. Sin

* Chileno. Profesor de Historia y Ciencias Sociales y Licenciado en Historia por la Universidad Austral de Chile. Estudiante Magister en Historia en Universidad de Santiago de Chile. Correo electrónico: bayronmvp@gmail.com

${ }^{2}$ Chaihuín está ubicado en la comuna de Corral, provincia de Valdivia, XIV Región de Los Ríos, Chile. 
embargo, lo cierto es que el PS atravesaba un complejo debate respecto a las estrategias para conquistar el poder, en el que se enfrentaban, por un lado, sectores que adherían férreamente a la vía electoral, y por otro, quienes proponían la necesidad de prepararse para la lucha armada.

Este debate táctico-estratégico tuvo sus raíces en dos procesos de cambio político-ideológico experimentados por el PS, los cuales comenzaron a darse, con mayor profundidad, desde fines de la década de 1950. El primero, denominado proceso de leninización, dice relación con el cuestionamiento de algunos sectores del PS a las alianzas con los sectores de centro y su progresivo acercamiento a la teoría leninista de la revolución, y el segundo, que llamaremos proceso de guevarización, tiene que ver con la influencia de las teorías de lucha guerrillera en el PS y en la izquierda en general. Ambos procesos de cambio político-ideológico alcanzaron su clímax en 1967, cuando en su XXII Congreso General el PS declaró, por primera vez, su carácter marxista-leninista y la inevitabilidad de la violencia revolucionaria.

En el presente trabajo reconstruimos la experiencia de la escuela de guerrilla de Chaihuín, comprendiendo este episodio no como un acontecimiento aislado, sino que como parte del largo proceso de cambio teórico experimentado por el PS entre los años '50 y '70. Por lo tanto, sugerimos que el nacimiento de la Organa al interior del PS y el desarrollo de la escuela de Chaihuín son explicables en tanto se comprenden como fruto de los procesos de leninización y guevarización que se dieron en el socialismo chileno.

Para desarrollar la investigación revisamos la prensa que cubrió el incidente del descubrimiento de la escuela, donde encontramos datos relevantes para la reconstrucción de esta historia (principalmente en declaraciones que distintos actores realizaron sobre el incidente). Además, contamos con valiosos testimonios de involucrados directa e indirectamente en la experiencia de la Organa y la escuela de Chaihuín, los cuales constituyen la principal fuente con la que realizamos este trabajo ${ }^{3}$.

\section{Leninización y guevarización del socialismo chileno}

No fue hasta el XXII Congreso de Chillán de 1967 que el PS se declaró, por primera vez, un partido de carácter leninista ${ }^{4}$. Sin embargo, el proceso de leninización del socialismo chileno comenzó algunos años antes, cuando sectores del PS comenzaron a cuestionar la política de alianzas con las burguesías nacionales que el partido implementó en sus primeras décadas. El sociólogo Tomás Moulian explica el proceso identificando dos momentos en la historia del socialismo chileno. El primero, caracterizado por el autor como el momento nacional-popular, tuvo lugar desde la fundación del PS en 1933 hasta 1957; y el segundo, identificado como un proceso de creciente leninización, se inició a partir de 19575 .

El primer momento propuesto por Moulian se caracterizó, entre otras cosas, por la activa participación del PS en los gobiernos de tipo frente popular, "donde desarrolló un programa de reformas democratizadoras, de fomento de la industrialización y de fortalecimiento del papel del Estado como regulador de desigualdades" ${ }^{6}$. Sin embargo, debido a que los avances de esta política no fueron los esperados por el PS, algunos sectores del socialismo cuestionaron la política de alianzas con los partidos representantes de la burguesía nacional, comenzando a convivir en el PS dos posiciones: "una tendencia

\footnotetext{
3 Como señalan Pablo Pozzi y Claudio Pérez, ante la escasez de documentación sobre las actividades armadas o militares de la izquierda, la "única forma de reconstruir y explicar estos procesos históricos desde las subjetividades políticas y desde los protagonistas para rescatar el recorrido militante de una generación, es a través del relato como fuente de ese pasado vivo". Pablo Pozzi y Claudio Pérez (editores), Historia oral e historia politica: Irquierda y lucha armada en América Latina, 1960-1990, Santiago, LOM Ediciones y Universidad Academia de Humanismo Cristiano, 2012, 16.

${ }^{4}$ Julio César Jobet, El Partido Socialista de Chile (II), Santiago, Editorial Prensa Latinoamericana, 1971, 130.

5 Tomás Moulian, Democracia y socialismo en Chile, Santiago, FLACSO, 1983, 85.

${ }^{6}$ Moulian, op. cit., 85.
} 
que definía al partido como una organización que promovía reformas desde el Estado"; y "una tendencia con pretensiones revolucionarias" 7 .

Desués de una frustrada participación en el gobierno de Carlos Ibáñez del Campo, el Partido Socialista Popular (PSP) ${ }^{8}$ profundizó el cuestionamiento a la participación de los socialistas en gobiernos con los partidos burgueses, estableciendo en su XV Congreso de 1953 la tesis de la "República Democrática de Trabajadores", que en resumen planteó que "la revolución democrático-burguesa, ineludible históricamente, debe comprenderse como una etapa de la revolución socialista, durante la cual

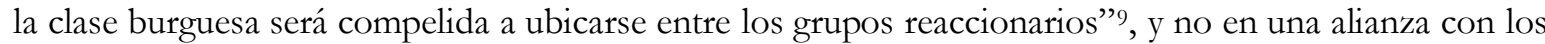
partidos del mundo popular. Esta idea fue profundizada en el XVI Congreso de 1955, en una tesis política que el socialismo denominó "Frente de Trabajadores", la cual apareció explicada en un boletín del Comité Central del PSP en diciembre de 1955:

Por nuestra parte, consideramos agotada la experiencia de los Frentes con la burguesía y los partidos burgueses, porque esos partidos no pueden ir contra intereses que hieren a las masas ya que estos intereses se confunden con los suyos. El Partido Radical y los social-cristianos tendrán que llegar siempre a la traición, llevando la desilusión a las masas movilizadas con esfuerzo y sacrificio que no pueden desperdiciarse. Por eso es necesario endurecer la lucha, hacerla más definitiva, con objetivos más revolucionarios (...) ello debería expresarse bajo la forma de un Frente de los partidos obreros y la Central Única de Trabajadores, o sea de un Frente de Trabajadores que lleve adelante una política de clase ${ }^{10}$.

En 1957 tuvo lugar el Congreso de Unidad, donde volvieron a encontrarse los socialistas agrupados en el PSP y el Partido Socialista de Chile. Entre sus acuerdos de reunificación destaca que adoptaron la tesis del "Frente de Trabajadores" elaborada por el PSP en tiempos de división ${ }^{11}$, cuestión que da cuenta de dos cosas importantes. Primero, que las diferencias ideológicas que provocaron la división del socialismo chileno se resolvieron en el marco de la leninización del partido, pues, como vemos, ambas fracciones que para entonces existían del PS se reunificaron en torno a la tesis que representó un acercamiento al marxismo-leninismo y un alejamiento de las definiciones que el partido sostuvo en sus primeros años. Segundo, que el socialismo chileno establece, desde entonces, priorizar la construcción de una alternativa con fuerzas de izquierda antes que con otros sectores de la política nacional (cabe destacar que esto se da únicamente a nivel de definiciones, pues en la práctica el socialismo chileno continuó estableciendo alianzas electorales con los partidos de centro).

A partir de lo anterior, con las tesis de la "República de Trabajadores" y del "Frente de Trabajadores", se inicia un proceso de redefinición político-ideológica del socialismo chileno que estuvo marcado por dos hitos importantes.

El primero corresponde a las elecciones presidenciales de 1964. El sorpresivo rendimiento de la izquierda en las elecciones de 1958 presagió la posibilidad de vencer en las urnas en 1964², pero la

\footnotetext{
7 Ibid, 86.

8 En 1948 el PS experimentó una división de sus filas por no acordar una única posición frente a la promulgación de la Ley de Defensa Permanente de la Democracia. El grupo que apoyó la promulgación de la ley conservó el nombre del Partido Socialista de Chile, mientras que, según Jobet, "el legítimo Partido Socialista" pasó a llamarse Partido Socialista Popular. Ambos grupos se reunificaron en 1957 prevaleciendo las definiciones políticas del PSP. Julio Cesar Jobet, El socialismo chileno a través de sus congresos, Santiago, Editorial Prensa Latinoamericana, 1965, 65.

9 Óscar Waiss, Nacionalismo y socialismo en América Latina, Buenos Aires, Ediciones Iguazú, 1961, 179.

10 Boletín del Comité Ejecutivo del PSP No 2, diciembre de 1955, en http://www.socialismo-chileno.org/bcc/bcc.html, consultado el 15/08/2017.

11 Resolución Política del Congreso de Unidad, 1957, Archivo Adonis Sepúlveda, en http://www.socialismochileno.org/adonis/caja2/2E/res_politica_congreso_unidad_1957_a.pdf, consultado el 20/11/2017.

12 Alejandro Chelen Rojas, Trayectoria del socialismo (apuntes para una historia crítica del socialismo chileno), Buenos Aires, Editorial Astral, $1966,120$.
} 
"Revolución en Libertad" de la Democracia Cristiana pudo imponerse victoriosa ante el Frente de Acción Popular (FRAP). Tras esto, al haber perdido la que parecía la mejor oportunidad electoral, la izquierda chilena sufrió un profundo impasse estratégico. Esto gatilló el cuestionamiento de la lucha electoral y abrió la búsqueda de "nuevas formas de lucha" al interior del PS ${ }^{13}$, definiendo en su XXI Congreso General de 1965 que "el partido tiene un objetivo, y para alcanzarlo deberá usar todos los métodos y los medios que la lucha revolucionaria haga necesarios"14. De esta manera, la derrota de 1964 implicó un nuevo giro ideológico en el socialismo chileno, restando sólo tres años para que oficialmente, en el XXII Congreso de Chillán de 1967, el PS plantee la inevitabilidad y legitimidad de la violencia revolucionaria y se declare un partido marxista-leninista. ${ }^{15}$

Por otro lado, otro factor que estimuló la leninización del socialismo chileno fue la desestalinización del comunismo soviético e internacional, la cual comenzó a darse con la muerte de Stalin en 1953 y se materializó formalmente en el XX Congreso del Partido Comunista de la Unión Soviética (PCUS), donde el entonces Primer Secretario del PCUS, Nikita Khrushchev planteó que el culto a Stalin se transformó en una perversión excesiva de los principios de partido y un pisoteo a los principios leninistas ${ }^{16}$. De este modo, según Moulian, "se derrumbó lo que constituía para los socialistas la principal barrera política, porque el leninismo como teoría se despojaba con la hipoteca estaliniana" ${ }^{7}$.

En el mismo periodo en que se desarrolla la leninización del PS, las ideas guevaristas sobre la lucha guerrillera comenzaron a influir en la izquierda chilena, y, especialmente, en el socialismo chileno. Esto se expresó, por ejemplo, en la formación de una sección chilena del Ejército de Liberación Nacional (ELN) del Che Guevara que estuvo integrada principalmente por militantes socialistas. Entre sus filas destacaron, entre otros, Elmo Catalán, Arnoldo Camú, Jaime Sotelo, Tirso Montiel, Walterio Fierro, Félix Huerta y Beatriz Allende ${ }^{18}$. Su primera misión, entre fines de 1967 y otoño de 1968, fue rescatar a los sobrevivientes de la guerrillera del Che en Bolivia ${ }^{19}$, para lo que formaron una red de apoyo clandestina. Un año después, a mediados de 1969, viajaría un grupo de elenos chilenos a integrar una nueva iniciativa guerrillera en Bolivia ${ }^{20}$.

Las definiciones del Congreso de Chillán y la creación de los elenos chilenos permiten ver la clara inclinación del socialismo chileno hacia posiciones pro lucha armada. Sin embargo, aun cuando gran parte del partido interpretó las tesis de Chillán como la necesidad de prepararse para un posible enfrentamiento, el PS se presentó a las elecciones de 1970 con altas expectativas en torno a la figura de Salvador Allende. Esto se explica considerando la importancia que ya tenía en el partido el fenómeno del "allendismo", el cual influenciaba, en distintos grados, a las diversas posiciones presentes en el socialismo. Por ejemplo, en un trabajo sobre la formación e identidad del ELN chileno, Pedro Valdés sostiene que por más que los socialistas que dieron forma a los elenos adhirieron profundamente al guevarismo, los principios del proceso que condujo Allende también fueron parte de su visión del proceso revolucionario ${ }^{21}$.

\footnotetext{
13 Joaquín Fermandois, La revolución inconclusa: La izquierda chilena y el gobierno de la Unidad Popular, Santiago, Centro de Estudios Públicos, 2014, 153.

14 Jobet, op. cit., 111

${ }^{15}$ El texto de las resoluciones del XXII Congreso de Chillán fueron publicadas en Punto Final. Ver "El Partido Socialista contra el reformismo", Punto Final, Suplemento a la edición N 46, enero de 1968.

16 Informe Secreto al XX Congreso del PCUS, Nikita Khrushchev, 25 de febrero de 1956, en https://www.marxists.org/espanol/khrushchev/1956/febrero25.htm, consultado el 25/08/2017.

17 Moulian, op. cit., 88.

18 Patricio Quiroga, Compañeros: el GAP: La escolta de Allende, Santiago, Editorial Aguilar, 2001, 21.

19 Pedro Valdés Navarro, "El proceso de formación del Ejército de Liberación Nacional y los Elenos chilenos", en Igor Goicovic, Julio Pinto, Ivette Lozoya y Claudio Pérez (compiladores), Escrita con sangre: Historia de la violencia en América Latina: Siglos XIX y XX, Santiago, Ceibo Ediciones, 2013, 328.

${ }^{20}$ Cristián Pérez, "El ejército del Che y los chilenos que continuaron su lucha”, Estudios Públicos, N 78, 2000, 181.

21 Pedro Valdés Navarro, El compromiso internacionalista. El Ejército de Liberación Nacional. Los elenos chilenos, 1966-1971. Formación e identidad, Santiago, LOM Ediciones, 2018, 111.
} 
Con todo lo anterior, en el marco de las elecciones de 1970 se generaron profundas contradicciones táctico-estratégicas al interior del PS, pues mientras unos se abocaron a trabajar para las elecciones presidenciales, otros discutían la forma de desarrollar las tesis de Chillán. En este contexto es que nace la Organa, el grupo que más tarde implementó la escuela de guerrilla de Chaihuín.

\section{El nacimiento de La Organa}

Los procesos de leninización y guevarización experimentados por el socialismo chileno que alcanzaron su clímax en las declaraciones del Congreso de Chillán de 1967, dieron paso a la formación de un grupo interno del PS denominado la Organa, el cuál nació con el objetivo de preparar las condiciones para un enfrentamiento armado.

La Organa nació en 1968, inmediatamente después de una movilización campesina conocida como la "Batalla del fundo San Miguel"22, en la que distintos sindicatos campesinos de la comuna de San Esteban, provincia de Los Andes, protagonizaron la toma de un fundo llamado San Miguel en respuesta a los latifundistas de la zona que se negaban a responder sus demandas. Esta experiencia, si bien no desencadenó un conflicto mayor, es importante porque, según Cristián Pérez, es la primera huelga campesina de carácter legal23, a la vez que "el primer incidente donde se visualiza la estrategia armada del PS"24. Del mismo modo, Jorge Arrate y Eduardo Rojas plantean que, en la batalla del fundo San Miguel, "da sus primeros pasos de acción directa el grupo o tendencia del PS que está por desarrollar su capacidad militar, en cumplimiento de los acuerdos del Congreso de Chillán”25.

En efecto, un sector de la militancia del PS participó de la batalla del fundo San Miguel principalmente a través de la Comisión Nacional Agraria Socialista (CONAS), la cual fue una entidad del partido encargada de los asuntos relacionados con los trabajadores del campo. Eduardo Olivares, militante socialista e integrante de la CONAS de la época, relata que: "era un organismo ligado a todo el tema de la reforma agraria, buscaba profundizar la reforma agraria (...). Era parte interna del partido y veía todo lo que era agrario" 26 . El protagonismo de la CONAS y el PS en la experiencia de San Miguel fue posible, principalmente, gracias a la posición de Rolando Calderón Aránguiz, quien para entonces era dirigente de la Confederación Campesina e Indígena Ranquil ${ }^{27}$, una de las federaciones de sindicatos campesinos más importantes del país. Del mismo modo, la senadora socialista e integrante de la CONAS, María Elena Carrera, cumplió un importante papel en el episodio del fundo San Miguel, acompañando a los campesinos y mediando con las autoridades policiales y gubernamentales"28.

Por otra parte, la CONAS permitió la participación de otros sectores de la militancia socialista en la experiencia de San Miguel, particularmente del sector juvenil y universitario. Esto lo concretó invitando a la toma del fundo a la Brigada Universitaria Socialista (BUS), que fue una estructura del PS cuyas tareas tuvieron que ver, principalmente, con la disputa política en las federaciones universitarias, el trabajo voluntario y el enfrentamiento contra fuerzas opositoras a la reforma universitaria. Renato Moreau, integrante de la BUS de la época, recuerda que: "Nos van a pedir apoyo los campesinos para la primera huelga legal campesina (...) la CONAS define tomarse el fundo San Miguel, entonces le van a

\footnotetext{
22 Fue llamada por primera vez así en un reportaje de la revista Punto Final en 1968. Ver "La batalla del fundo San Miguel", Punto Final, No 61, agosto de 1968.

${ }^{23}$ En abril de 1967 fue promulgada bajo el gobierno de Eduardo Frei Montalva la Ley de Sindicación Campesina, la cual reguló la formación de sindicatos campesinos y estableció ciertos derechos que los latifundistas debían respetar a los trabajadores de sus predios, en https:/ /www.leychile.cl/Navegar?idNorma=28586, consultado el 20/11/2017.

${ }^{24}$ Cristián Pérez, "Guerrilla rural en Chile: La batalla del fundo San Miguel (1968)", en Estudios Públicos, N 78, $2000,181$.

25 Jorge Arrate y Eduardo Rojas, Memorias de la irquierda chilena: Tomo I (1850-1970), Santiago, Ediciones B, $2003,433$.

${ }^{26}$ Entrevista a Eduardo Olivares, 17 de agosto de 2017.

27 Quiroga, op. cit., 29.

28 “Los sucesos del fundo San Miguel”, Punto Final, N 61, agosto de 1968.
} 
pedir ayuda a la BUS y básicamente querían alguien especialista en molotov"29. Según Patricio Quiroga, entre los universitarios que se designaron para la acción estuvieron Enrique Dávalos, Boris Bronstein, Hernán Coloma y Renato Moreau ${ }^{30}$.

Después de la experiencia del fundo San Miguel, todo este grupo de orgánicas y militantes que compartían la necesidad de prepararse para la lucha armada, concluyeron que era necesaria una herramienta política que permitiera implementar las definiciones del XXII Congreso de Chillán. Esto, puesto que, según sus análisis, los "guatones" 31 no estaban a la altura de las circunstancias, y el "ELN chileno, por su condición de columna clandestina y dependiente del Estado Mayor del ELN boliviano, tampoco estaba en condiciones de dirigir el proceso de acumulación de fuerzas en Chile" 32 . Por estas razones, los socialistas involucrados en el conflicto de San Miguel determinaron fundar la Organa.

Tras su formación, los socialistas de la Organa intentaron expandir sus ideas entre los sectores donde tenían mayor presencia, logrando así influir a grupos de campesinos, obreros y estudiantes ${ }^{33}$. Esto, se dio porque las orgánicas que dieron vida a la Organa tenían presencia en dichos sectores, principalmente en la Universidad de Chile y en la Confederación Campesina e Indígena Ranquil ${ }^{34}$. Según Quiroga, "aquí radicaba la diferencia básica con el ELN. Los dirigentes de la Organa no participaban de la teoría del foco revolucionario y subordinaban el aspecto militar a la concepción de movilizar actores sociales políticamente activos" 35 . Esto coincide por lo expuesto por Moreau, quien señala que la Organa nunca tuvo por objetivo crear focos guerrilleros, sino que más bien, buscaba formar cuadros políticos con conocimiento en la lucha militar, considerando que cualquiera que fuese el resultado de las elecciones, en la lucha por el socialismo era inevitable el conflicto armado ${ }^{36}$. Por lo anterior, los principales esfuerzos de la Organa estuvieron orientados a constituir centros de instrucción guerrillera.

\section{La experiencia de la escuela de guerrilla de Chaihuín}

En septiembre de 1969, aproximadamente un año después del episodio del fundo San Miguel, Néstor Figueroa recomendó a la Organa levantar una escuela de instrucción guerrillera en Chaihuín ${ }^{37}$, localidad costera cercana a la ciudad de Valdivia (XIV Región de Los Ríos). En ese entonces, Néstor era, además de miembro de la Organa, un destacado dirigente ferrocarrilero en Valdivia y uno de los líderes del PS en la región. Era apodado por sus más cercanos como Nikita Khrushchev, producto de su perfil serio e intelectual que lo asimilaba al dirigente ruso ${ }^{38}$. La recomendación de Néstor no era, por lo tanto, algo desestimable, pues venía de un militante destacado y conocedor de la zona.

De esta manera, la Organa comenzó los preparativos para levantar una escuela de guerrilla en el sur $^{39}$, siendo Chaihuín el lugar escogido para la operación. Este sector, debido a la geografía característica del lugar, resultaba idóneo para desarrollar una experiencia de este tipo. Chaihuín, hasta el día de hoy, es un poblado pequeño que no cuenta con más de 40 habitantes ${ }^{40}$, levantado junto a un río que cruza el caserío y a tan solo pasos de la costa del océano Pacífico. Está rodeado de cerros otrora cubiertos por el frondoso bosque valdiviano, caracterizado por la abundancia y diversidad de vegetación propia de climas lluviosos. Entre las especies del sector destacan, entre otras, los alerces, helechos, olivillos y arrayanes.

\footnotetext{
${ }^{29}$ Entrevista a Renato Moreau, 15 de mayo de 2017.

30 Quiroga, op. cit., 30.

31 Denominación informal de los sectores menos radicalizados (reformistas) del PS.

32 Quiroga, op. cit., 34.

33 Ibid, 41.

34 Entrevista a Renato Moreau, 15 de mayo de 2017.

35 Quiroga, op. cit., 41.

36 Entrevista a Renato Moreau, 15 de mayo de 2017.

${ }^{37}$ Quiroga, op. cit., 42.

38 Entrevista a Eduardo Olivares, 17 de agosto, 2017.

39 Entrevista a Renato Moreau, 15 de mayo de 2017.

40 Instituto Nacional de Estadísticas (INE), Chile: ciudades, pueblos, aldeas y caseríos, 2005, 239.
} 
Meses antes el sector había sido visitado por miembros de la Organa mientras realizaban trabajos de sindicalización campesina por medio de la Confederación Campesina e Indígena Ranquil, por lo que el lugar ya era reconocido como favorable para la realización de operaciones secretas. Al respecto Moreau recuerda:

En el verano del '69 nosotros mandamos grupos de estudiantes al Sur a hacer trabajo de sindicalización campesina por la Ranquil. Nuestra función era crear sindicatos de campesinos, de pequeños propietarios, y teníamos que ver posibles zonas para hacer escuelas de guerrilla. Yo fui a Loncoche y Pucón y ahí nos tiramos para Valdivia. Yo me quede abajo y otros siguieron a Chaihuín, aunque no alcanzaron a llegar allá mismo ${ }^{41}$.

En esta ocasión era importante escoger adecuadamente el lugar, pues la Organa venía saliendo de un esfuerzo frustrado por sostener una escuela de guerrilla en Guayacán, localidad ubicada en la zona cordillerana del Cajón del Maipo, a 30 o 40 kilómetros de Santiago. ${ }^{42}$. Había sido su primera experiencia desarrollando instrucción guerrillera, pero fracasó por una serie de factores que los militantes no contemplaron. Sin embargo, aun cuando la escuela de Guayacán fue relativamente efímera, es importante porque es donde comienza a gestarse la experiencia de Chaihuín.

\section{De Guayacán a Chaihuín}

La escuela de Guayacán fue creada por la Organa entre marzo y abril de 1969, alcanzando a pasar por ella un grupo de 15 militantes que estuvo bajo el mando de Jaime Sotelo ${ }^{43}$, militante de la Organa que se mantiene desaparecido desde su detención en La Moneda el día del golpe de Estado ${ }^{44}$. Sotelo había vuelto recién de un curso militar en Cuba y se puso a disposición de la Organa para formar cuadros político-militares en Chile ${ }^{45}$. Pese al rápido descubrimiento y desarticulación de la escuela de Guayacán, en ella la Organa puso por primera vez en práctica las jornadas de instrucción guerrillera que emplearía más tarde en Chaihuín. Renato Moreau, quien participó tanto en la escuela de Guayacán como en la de Chaihuín, recuerda que: "En Guayacán se hacía armamento popular, minas, hasta un pequeño lanzacohetes con latas, las soldábamos. También un curso de seguridad, salíamos en las noches a montes a hacer algunas explosiones, a practicar" 46.

El campamento de Guayacán cayó al poco tiempo de haber comenzado a funcionar, pero alcanzaron a completar su formación los 15 militantes que participaron de la experiencia. Es más, la escuela fue descubierta el último día cuando realizaban una celebración y festejaban la finalización de las jornadas de entrenamiento ${ }^{47}$. Tras la desarticulación de la escuela, la policía elaboró un informe en el que se aprecian, por un lado, las características de la formación que recibían los militantes, y por otro, la visión que tenían las autoridades de la época frente a las iniciativas de este tipo:

(...) una importante y fuerte cantidad de elementos explosivos, sustancias químicas para su fabricación, algunas armas, municiones, herramientas, documentos y materiales que demuestran claramente que en tal lugar funcionaba una escuela o centro de instrucción y adiestramiento de guerrilleros, terroristas, saboteadores, milicianos y grupos de combate armado. (...) Allí se efectuaban clases y cursos de técnica y adiestramiento de guerrilleros y milicianos armados, los que permanecían

\footnotetext{
41 Entrevista a Renato Moreau, 15 de mayo de 2017.

42 Quiroga, op. cit., 42.

43 Entrevista a Renato Moreau, 15 de mayo de 2017.

44 Informe de la Comisión Nacional de Verdad y Reconciliación, Tomo I, 1996, p. 120.

45 Entrevista a Renato Moreau, 15 de mayo de 2017.

46 Entrevista a Renato Moreau, 15 de mayo de 2017.

${ }^{47}$ Entrevista a Hernán Coloma, 9 de septiembre, 2017
} 
concentrados durante un lapso de tiempo en el cual se desarrollaban las clases teóricas y prácticas, de lucha armada, sabotaje, terrorismo, insurrección, seguridad y toda clase de temas revolucionarios. ${ }^{48}$

La corta experiencia de Guayacán no solamente fue el comienzo de un modo de instrucción guerrillera que continuaría en Chaihuín, sino que, además, significó la aparición pública de un nuevo grupo en Chile que adhería a la lucha armada ${ }^{49}$. De esta manera, tras la frustrada experiencia de Guayacán, la Organa traslado sus esfuerzos al sur para instalar la escuela de guerrilla de Chaihuín.

\section{Levantando el campamento en Chaihuín}

El encargado de montar la escuela de Chaihuín fue Hernán Coloma, el mismo que había participado como estudiante en la experiencia del fundo San Miguel. Recibió la orden de ingresar a las montañas del sector de Chaihuín y buscar un lugar para levantar el campamento. Llegó a Valdivia junto a Renato Moreau, militante socialista que, como vimos, participó como alumno en la escuela de guerrilla de Guayacán.

En Valdivia fueron recibidos por Néstor Figueroa, quien les entregó una carpa y las vituallas necesarias para pasar algunos días bajo el crudo invierno de la zona. Tras este encuentro se dirigieron a Corral, desde donde partieron a Chaihuín y se adentraron en los bosques buscando "un claro que tuviera las condiciones necesarias para hacer un campamento" 50 .

En medio del bosque, un campesino del lugar los encontró y les ofreció refugio. "Una vez secos y habiendo saciado el hambre, nos dormimos profundamente contra toda medida de seguridad", rememora Coloma. Tras dos días abriendo senderos, los militantes hallaron un lugar que les pareció idóneo para la instalación del campamento.

El lugar escogido por la Organa fue un fundo de propiedad privada llamado, al igual que el pueblo, Chaihuín. Este se ubicaba en el cerro Las Garzas y estaba prácticamente deshabitado, pues era propiedad de la Condesa María Teresa Lebauty, quien para entonces residía en París ${ }^{51}$. Las condiciones del lugar eran bastantes adversas para la sobrevivencia humana, lo que hacía difícil imaginar la posibilidad de que personas mantengan durante meses jornadas de entrenamiento militar. El entonces administrador del fundo, Aldo Guido Fontecilla, señaló que, si bien el lugar permite obtener un sustento natural, "climáticamente destruye a cualquier persona no habituada a estos rigores" 52.

Una vez escogido el lugar, Coloma y Moreau se dispusieron a levantar el campamento. En el transcurso de los días, Moreau debió trasladarse a Valdivia para recibir atención médica producto de un accidente sufrido en su pierna mientras recorría los vericuetos de la zona ${ }^{53}$. Para Coloma sería más difícil trabajar durante algunos días solo, pero era menester cumplir con la tarea encomendada por la Organa. El campamento debía levantarse antes de enero sin posibilidad de retraso.

La fecha escogida para el inicio de las actividades de la escuela no fue definida de manera arbitraria, sino que fue parte de la estrategia ideada por la Organa para posibilitar la llegada de los participantes de la escuela al lugar ${ }^{54}$.

48 Archivos Judiciales de Santiago, "Causa contra Jorín Pilowsky y otros", en Eugenia Palieraki, jLa revolución ya viene!: El MIR cbileno en los años sesenta, Santiago, LOM Ediciones, 357.

${ }^{49}$ Quiroga, op. cit., 42.

50 Entrevista a Hernán Coloma, 9 de septiembre, 2017.

51 "400 policías cercan el foco guerrillero: Seis los detenidos", La Segunda, 25 de mayo de 1970.

52 "Búsqueda de guerrilleros: 400 carabineros acordonan Corral", La Segunda, 25 de mayo de 1970.

53 Entrevista a Hernán Coloma, 9 de septiembre de 2017.

${ }^{54}$ Entrevista a Renato Moreau, 15 de mayo de 2017. 


\title{
La llegada al campamento: La Organa y los trabajos voluntarios de la FECh
}

Ya montado el campamento, había que esperar el verano para que llegase el primer contingente de militantes que participaría de la escuela. No era una operación sencilla. En un pueblo como Chaihuín, donde la población era tan pequeña que entre los lugareños se conocían y donde no se recibían regularmente visitas de afuerinos, cualquier movimiento de personas ajenas al sector llamaba la atención.

Para concretar la llegada del primer grupo al lugar, la Organa utilizó, por un lado, la influencia que tenía en la Federación de Estudiantes de la Universidad de Chile (FECh) a través de la BUS, y por otro, los trabajos voluntarios estudiantiles que se daban en el marco de la reforma universitaria.

Los años sesenta y setenta fueron tiempos de movilización estudiantil. Se demandaba una transformación en el rol social de las instituciones de educación superior; se discutía sobre cómo acercar la universidad al pueblo ${ }^{55}$. En este escenario, la FECh organizaba comprometidas jornadas de trabajo voluntario en distintas comunas y regiones del país, con el objetivo de vincular a los estudiantes de sus carreras con las necesidades que aquejaban al Chile de la época. Ante esto, aprovechando su presencia en la Universidad de Chile a través de la BUS, la Organa operó de tal manera para que en verano de 1970 el destino de los trabajos voluntarios sea Chaihuín ${ }^{56}$.

La operación no tuvo mayores dificultades. La BUS tenía una importante presencia en las carreras del área de la salud -medicina, odontología, enfermería, entre otras-, que resultaban ser de donde más salían estudiantes a trabajar como voluntarios ${ }^{57}$. Entre sus miembros de la facultad destacaron, entre otros, Ennio Vivaldi, Félix Huerta y Carlos Lorca ${ }^{58}$. Lorca para entonces era estudiante de medicina y dirigente de la $\mathrm{FECh}^{59}$, cuestión que facilitó que la estrategia de la Organa fuese adoptada por los organizadores de los trabajos voluntarios. En la misma fecha, según consigna el periódico Noticias de Última Hora, también llegaron al lugar estudiantes secundarios a realizar trabajos con los obreros madereros de la zona ${ }^{60}$. Respecto a esta operación Renato Moreau recuerda que:

\begin{abstract}
Nosotros habíamos ideado trabajos voluntarios de la FECh, nosotros estábamos metidos en la FECh, entonces ideamos trabajos voluntarios donde iba un lote de gente de medicina, dentistas, donde el jefe del lote, de dos lotes que fueron pa'lla, serían de la Organa. Eso nos permitiría que salieran o entraran estudiantes, entonces poder entrar a la zona sin que se notara. Era para poder meternos a la zona y que dijeran que son los estudiantes los que andan ${ }^{61}$.
\end{abstract}

Los voluntarios que llegaron a Chaihuín realizaban principalmente trabajos de asistencia médica dada las carreras que cursaban en la universidad-y alfabetización. El entonces cuidador del fundo donde se emplazó la escuela de guerrilla recuerda que "efectivamente en febrero llegaron hasta el fundo un grupo de estudiantes que iban a realizar labores de alfabetización" ${ }^{62}$.

Después de lograr que los trabajos voluntarios se realicen en Chaihuín, la estrategia de la Organa fue meter a sus militantes entre los dos grandes grupos de estudiantes que se dirigieron al lugar. De esta manera, mientras los estudiantes realizaban los trabajos voluntarios, los miembros de la Organa se dirigieron silenciosamente hacia el campamento levantado por Coloma y Moreau ${ }^{63}$.

\footnotetext{
55 Alejandro Rojas, "La utopía iba a ser nuestra", Anales de la Universidad de Cbile, Sexta Serie, N¹7, 2005, 185.

56 Entrevista a Renato Moreau, 15 de mayo de 2017.

57 Entrevista a Renato Moreau, 15 de mayo de 2017.

58 Juan Azócar Valdés, Lorca: Vida de un socialista ejemplar, Santiago, Ediciones Radio Universidad de Chile, $2015,30$.

59 Azócar, op. cit., 31.

60 "Entre los detenidos está el presidente de secundarios", Noticias de última hora, 26 de mayo de 1970.

${ }^{61}$ Entrevista a Renato Moreau, 15 de mayo

62 "Búsqueda de guerrilleros: 400 carabineros acordonan Corral", La Segunda, 25 de mayo de 1970.

${ }^{63}$ Entrevista a Renato Moreau, 15 de mayo de 2017.
} 
Este primer contingente, según recuerda Moreau, estuvo integrado por al menos 25 militantes entre los que se encontraban hombres y mujeres ${ }^{64}$. Al comienzo tanto Coloma como Moreau estuvieron a cargo del grupo, pero al poco tiempo Moreau debió bajar a Valdivia para preparar la llegada de la segunda cuadrilla ${ }^{65}$. De este modo, Coloma fue quien lideró durante el verano la experiencia de los primeros estudiantes de la escuela de guerrilla de Chaihuín.

Ya en el campamento, los militantes iniciaron su formación guerrillera en las instalaciones que habían logrado levantar Coloma y Moreau. Las jornadas constaban de distintas tareas en las que los militantes se perfeccionaban en diversas aristas del enfrentamiento militar. Se hacía práctica de tiro en un polígono improvisado con los materiales disponibles en la zona ${ }^{66}$ y se realizaban entrenamientos de supervivencia ${ }^{67}$. El lugar era ideal para estas acciones si se considera que el terreno de los alrededores de Chaihuín se caracterizaba por tener pendientes cubiertas por la tupida flora de la selva valdiviana.

Además, el entrenamiento físico se complementaba con arduas jornadas de formación teórica en las que se aprendía sobre arte combativo, teoría revolucionaria y confección de armamento y explosivos simples. Para esto contaban con una importante cantidad de textos que pudieron haber transportado los estudiantes voluntarios que llegaron al lugar. Tras la desarticulación de la escuela la prensa informó la existencia de una verdadera "biblioteca guerrillera" que contaba con una gran cantidad de "manuales de instrucción"68.

En el siguiente relato de Holzapfel de cuando visitó el campamento tras la desarticulación de la escuela, encontramos una imagen de la infraestructura del lugar:

(...) acerté vislumbrar que bajo unas grandes matas de quila había una construcción bajísima con techo de un agua forrado con nylon, sobre la cual habían extendido helechos que aún estaban verdes; asomándose por un pedazo de carpa suelta constaté una larga estancia cuya estructura era únicamente de coligüe, incluso el palillaje del piso. Era evidente que aquello era el dormitorio con capacidad para unas 20 personas. Había otra construcción pequeña y cuadrada, igualmente camuflada a la perfección, que habría hecho las veces de armería y una cancha de tiro al blanco en miniatura. Un largo tablero de palillos de quila muy bajo que seguramente funcionaba de comedor sin sillas. Y en una excavación para basura estaba la evidencia de la presencia de mujeres ${ }^{69}$.

No obstante la preparación previa, la experiencia del primer contingente que paso por Chaihuín no fue del todo exitosa. Coloma no recuerda con gratitud aquellos días, pasaron hambre, se perdía el pan que hacían, el apoyo logístico se demoraba en llegar y presionaba el miedo a ser descubiertos. Con el tiempo Coloma recuerda que:

A principios de enero tuve contacto con dos contactos que había hecho durante la permanencia solitaria, un lonco mapuche y un camionero que trabajaba con la empresa forestal que explotada el alerce más arriba de donde estábamos. Ambos me dijeron que debíamos retirarnos porque ya era conocida ampliamente nuestra presencia en la zona $^{70}$.

\footnotetext{
${ }^{64}$ Por la basura encontrada después de desarticular la escuela, el entonces Intendente de Valdivia señaló que era posible inferir la presencia de mujeres en el campamento. Joaquín Holzapfel Anwandter, Calle Calle, Valdivia, Ediciones de la Universidad Austral, 2007, 57.

${ }^{65}$ Entrevista a Renato Moreau, 15 de mayo de 2017.

66 Entrevista a Renato Moreau, 15 de mayo de 2017.

67 "Más refuerzos a zona del foco guerrillero", La Segunda, 26 de mayo de 1970.

68 "Biblioteca guerrilla encontró la policía en Chaihuín”, La Prensa, 27 de junio de 1970.

${ }^{69}$ Holzapfel, op. Cit., 57.

${ }^{70}$ Entrevista a Hernán Coloma, 9 de septiembre, 2017.
} 
Tras este episodio, Coloma viajó a Santiago para informar sobre la situación y se contactó con Rolando Calderón, para entonces dirigente del PS y de la Organa. Le planteó finalizar las actividades de la escuela de Chaihuín porque el riesgo de la caída era inminente, pero la Organa decidió continuar con la experiencia. Coloma desconcertado regresó a Chaihuín y continuó con las jornadas de entrenamiento. En marzo, ya finalizados los trabajos voluntarios de la FECh, el primer contingente de la escuela se retiró del lugar ${ }^{71}$.

\title{
El segundo contingente y la caída de Chaihuín
}

Después de que el primer grupo abandonó la escuela, subió al lugar un segundo contingente en un contex to totalmente distinto al de dos meses atrás. En primer lugar, ya no había trabajos voluntarios realizándose en la zona, lo que significó, por un lado, mayores dificultades para que los militantes llegaran al sector, y por otro, que no tuviesen abastecimiento constante de lo necesario para pasar los días.

En segundo lugar, en marzo de 1970 ya comenzaban los preparativos para la campaña de la Unidad Popular, lo que, según Moreau, provocó desorientación en los objetivos de la Organa ${ }^{72}$. Esto era entendible si consideramos que algunos miembros de la Organa eran también militantes destacados del PS, por lo que debían responder a sus distintas responsabilidades partidarias.

Lo anterior, más la difícil experiencia del primer contingente de la escuela, llevó a que por precaución el segundo grupo estuviera integrado sólo por seis militantes: Renato Moreau -quien lideró el grupo-; Rigo Quezada -militante del PS y dirigente de la Federación de Estudiantes Secundarios de Santiago (FESES); Sergio Torres, Luis López, Víctor Muñoz y Jaime Briones -los cuatro últimos identificados como obreros-73.

Es posible saber, gracias al testimonio de Moreau, que de estos seis integrantes no todos eran socialistas. Entre ellos había militantes del Movimiento Revolucionario Manuel Rodríguez (MR-2) ${ }^{74}$, el cual se había formado tras una división del MIR en 1969 y cuyo líder principal fue Rafael Ruiz Moscatelli. La Organa invitó al MR-2 a participar en forma de agradecimiento porque meses antes les entregaron la mitad del botín conseguido en un asalto al supermercado "Portofino" de Nuñoa ${ }^{75}$. Al respecto Moreau señala:

\begin{abstract}
Llevamos a Chaihuín a tres compañeros, dos en la primera y otro en la segunda, que eran del MR-2. (...) El jefe del MR-2 era Rafael Ruiz Moscatelli. Ellos hacen un asalto, como en mayo o julio de 1969, al Portofino, que es un supermercado, la mitad del botín se lo entregaron a la Organa y nosotros les entregamos algunas armas por solidaridad, entonces nuestra vinculación con el MR-2 era bastante cercana y llevamos a alguna gente a instruirse a Chaihuín. ${ }^{76}$
\end{abstract}

En esta ocasión la operación de llegada no fue tan sencilla. Las advertencias hechas por Coloma sobre el posible descubrimiento de la escuela obligaban al segundo grupo a ser mucho más cautos, a pasar lo más desapercibidos posible. Para esto, debieron recurrir a lugareños cercanos para que colaborasen con su traslado hasta la escuela.

Primero llegaron a Valdivia. Desde Valdivia viajaron en bote directamente hasta Chaihuín, sin pasar como se acostumbra por Corral. Llegaron a una casa que se encontraba en la orilla de la playa donde

\footnotetext{
71 Entrevista a Hernán Coloma, 9 de septiembre, 2017.

72 Entrevista a Renato Moreau, 15 de mayo, 2017.

73 "Los revolucionarios deben prepararse", Punto Final, N 107, martes 23 de junio de 1970.

${ }^{74}$ Los testimonios nos dejan ver que Moreau, Quezada y Torres eran socialistas. No hay claridad respecto a la militancia de los otros tres, pero por lo menos dos eran miembros del MR-2. Según la prensa de la época todos eran militantes socialistas, cuestión que desmintieron los protagonistas entrevistados.

75 “Gangsters o revolucionarios?, Punto Final, N 87, martes 9 de septiembre de 1969.

${ }^{76}$ Entrevista a Renato Moreau, 15 de mayo, 2017.
} 
vivía una familia de apellido Antillanca ${ }^{77}$. Llegaron como pudieron, recuerda Rigo Quezada, porque la casa no tenía un muelle habilitado para recibir embarcaciones. ${ }^{78}$.

Una vez en Chaihuín, los militantes subieron por las montañas hasta llegar al campamento abandonado por el primer grupo. Se instalaron y dieron inicio a las jornadas de entrenamiento bajo el mando, en esta ocasión, de Renato "el Tata" Moreau ${ }^{79}$. A los pocos días de iniciado el entrenamiento, comenzaron a sentir las duras condiciones por las que pasó el primer grupo, a lo que se sumó el crudo invierno que ya se dejaba caer.

A la semana llegó un "enlace" 80 a comunicarle a Moreau que debía viajar a una reunión en Santiago. Siguiendo la orden bajó a Valdivia, donde Nestor y Uldaricio Figueroa ${ }^{81}$ le facilitaron un pasaje para irse en tren hacia la capital. En Santiago asistió a una reunión de la dirección de la Organa en la sede Arauco del PS, en la que se discutió, entre otras cosas, la viabilidad de la continuación del campamento. Moreau dio cuenta de las adversidades que estaban viviendo y propuso terminar con el campamento hasta el próximo verano. La respuesta fue negativa, el campamento seguía por decisión de la dirección de la Organa ${ }^{82}$.

Disciplinadamente Moreau regreso a Chaihuín. Retomó el entrenamiento con los 5 militantes mientras esperaban, según lo planificado, la llegada de más gente. Por seguridad construyeron unas cavernas en las que esconderían las cosas en caso de ser descubiertos, pues aún persistía el miedo porque su presencia en el lugar ya era conocida ${ }^{83}$.

Pasaron algunos días hasta que llegó, inesperadamente, Jorge Federico Barraza, militante de la Organa conocido como "el Kiko". Había viajado hasta el lugar para comunicarle a Moreau la decisión de terminar con el campamento ${ }^{84}$, ante lo cual el grupo comenzó los preparativos para retirarse.

Más tarde, el día 20 de mayo de 1970, Moreau les daba una última práctica de tiro a los militantes mientras el Kiko fue a un antiguo campamento a revisar que no quedara nada. Entre eso, Moreau sintió que explotaba un estopín que habían diseñado a modo de alarma en una de las entradas, por lo que se dirigió al lugar pensando que el Kiko se había tropezado con el artefacto. Para mala sorpresa de él, se encontró con un grupo de Boinas Negras que, tras una larga búsqueda en los alrededores de Chaihuín, habían dado con el campamento de la escuela de guerrilla. Estaban completamente armados, listos para enfrentarse a un supuesto foco guerrillero que operaba en la zona.

Para entonces, miembros del Ejército de Chile ya habían recibido instrucción contrainsurgente en la Escuela de las Américas, por lo que los Boinas Negras que desarticularon el campamento en Chaihuín debieron haber tenido conocimiento sobre tácticas de enfrentamiento contra grupos guerrilleros ${ }^{85}$. $\mathrm{Al}$ decir de Lesley Gill, "la presencia de los militares chilenos en la Escuela de las Américas había crecido en los años 1950 y 1960, y el impacto de tantos años de entrenamiento del cuerpo de oficiales chilenos ya se notaba en la década de los años 70" 86 .

\footnotetext{
77 Entrevista a Rigo Quezada, 22 de abril, 2017.

${ }_{78}$ Entrevista a Rigo Quezada, 22 de abril, 2017.

${ }^{79}$ Entrevista a Renato Moreau, 15 de mayo, 2017.

80 Persona encargada de mantener comunicados a los participantes de la escuela de guerrilla con la dirección política de la Organa. 81 Para ese entonces ambos eran dirigentes ferrocarrileros en Valdivia. Moreau recuerda que viajó en un tren donde fue tratado con mucha amabilidad por el auxiliar producto de viajar recomendado por Néstor y Uldaricio.

82 Entrevista a Renato Moreau, 15 de mayo, 2017.

83 Entrevista a Renato Moreau, 15 de mayo, 2017.

${ }^{84}$ Entrevista a Renato Moreau, 15 de mayo, 2017.

85 Entre 1963 y 1966 participó en la Escuela de las Américas el militar chileno Eduardo Iturriaga Neumann, quien más tarde estuvo segundo al mando del batallón de Boinas Negras y asumió como jefe del Departamento Extranjero de la DINA. Ver J. Patrice Mc Sherry, Estados depredadores: la Operación Cóndor y la guerra encubierta en América Latina, Santiago, LOM Ediciones, 2009, 112.

86 Lesley Gill, Escuela de Las Américas: Entrenamiento militar, violencia politica e impunidad en las Américas, Santiago, LOM Ediciones, 2005, 112.
} 
La primera reacción de los Boinas Negras fue disparar "dos ráfagas cortas con sus armas automáticas" 87 , ante lo cual Moreau se lanzó al suelo para evitar salir herido. Los otros 5 militantes se movieron hasta sus puestos de defensa y distrajeron a los Boinas Negras, generando una oportunidad de escape que aprovecharon para fugarse del lugar. ${ }^{88}$ Kiko Barraza, que había ido al antiguo campamento para cerciorarse de que no quedara nada, no se encontraba en el momento que llegaron los Boinas Negras por lo que el grupo escapó sin él.

Tras el episodio, los militantes deambularon durante dos días entre las montañas de Chaihuín, teniendo que enfrentarse a una lluvia interminable y a la hostil naturaleza de la zona. Sobrevivieron con nada más de que "una lata y cuarto de Milo, dos cabezas de ajo, 300 gramos de pescado seco, tres papas crudas y un tarro y medio de Nescafé", además de algunos alimentos que ofrecía la naturaleza, como nalcas, helechos y raíces. La primera noche pernoctaron en un pequeño refugio construido con quilas, el cual fue destruido rápidamente por la intensa lluvia que asediaba el lugar. Fue imposible hacer fuego, lo que los obligó a consumir en su larga marcha sólo alimentos secos.

El segundo día de marcha perdieron en dos oportunidades el sentido de la orientación, cuestión que los llevó a deambular en círculos entre las montañas de las que intentaban escapar. Esto les provocó una especie de sicosis de inseguridad, señalaron meses después de la experiencia, pero afortunadamente la moral del grupo era alta y pudieron conservar los ánimos ${ }^{89}$

Llegando el alba del día 22 de mayo, para favor de los militantes las condiciones del tiempo tendieron a mejorar. Esto permitió que uno de los militantes trepara hasta la copa de un árbol para avistar mejor el camino, desde donde creyó observar a lo lejos el mar. Avanzaron en esa dirección con el objetivo de salir hacia la costa, pero entraron en una maraña de quilas casi impenetrable que los hizo perder el rumbo ${ }^{90}$. Más tarde, cuando la noche ya estaba encima, los militantes decidieron dirigirse donde un campesino que tenía contacto con Moreau, pero no pudieron burlar el cerco policial instalado para vigilar el sector ${ }^{91}$.

De esta manera, Renato Moreau; Rigo Quezada; Sergio Torres, Luis López, Víctor Muñoz y Jaime Briones, fueron detenidos por carabineros el día 22 de mayo de 1970, después de casi 5 meses de funcionamiento del campamento en Chaihuín. Se hizo pública la existencia de la escuela de guerrilla y con ello se abrió un complejo debate político en medio de la campaña de la UP. Luego de la detención, permanecieron durante 48 horas en un rancho cercano, hasta que el día 24 fueron trasladados a Corral para luego ser llevados a la Cárcel de Valdivia ${ }^{92}$. Ahí permanecieron incomunicados por orden del magistrado Alejandro Araya Flores ${ }^{93}$, pudiendo hablar recién con el exterior el 5 de junio de 197094 . Hasta aquí parecía estar todo en orden para las autoridades, sin embargo, estas no sabían que aún faltaba un militante que se encontraba en el campamento al momento de su desarticulación: Jorge Federico Barraza Barry, el "Kiko".

\section{La desaparición de "Kiko" Barraza}

Cuando los Boinas Negras asaltaron por sorpresa el campamento de la escuela, el "Kiko" Barraza aún no volvía del antiguo campamento que había ido a revisar. Por lo tanto, no logró escapar junto al

\footnotetext{
87 El 23 de junio de 1970 los participantes de la escuela hablaron con Punto Final sobre el episodio del descubrimiento del campamento. "Los revolucionarios deben prepararse", Punto Final, № 107, martes 23 de junio de 1970.

88 "Los revolucionarios deben prepararse", Punto Final, N 107, martes 23 de junio de 1970.

89 Idem.

90 "Los revolucionarios deben prepararse", Punto Final, N 107, martes 23 de junio de 1970.

${ }^{91}$ Entrevista a Renato Moreau, 15 de mayo, 2017.

92 "Los revolucionarios deben prepararse", Punto Final, N 107, martes 23 de junio de 1970.

93 "Incomunicados los extremistas", La Prensa, miércoles 27 de mayo de 1970.

94 "En libre plática los guerrilleros", La Prensa, viernes 5 de junio de 1970.
} 
resto de sus compañeros, pero, al parecer, tampoco fue detenido por las fuerzas policiales que cercaron el lugar.

$\mathrm{Al}$ ser interrogados por las autoridades policiales, los militantes apresados guardaron silencio sobre la presencia de "Kiko" Barraza, pensando en la remota posibilidad de que hubiese logrado escapar. "Si hablábamos de él lo buscarían por todas partes", recuerda Quezada, por lo que prefirieron señalar que sólo eran los $6 .{ }^{95}$ Luego, estando incomunicados, Néstor Figueroa logró evadir la seguridad del recinto penitenciario y se comunicó con los presos a través de un papelito, a través del cual le informaron que faltaba el "Kiko" 96. Figueroa intentó movilizar a la Organa para encontrar al "Kiko", pero la presencia policial y militar en el sector dificultaba desplegar cualquier esfuerzo militante.

No sería hasta 1971 que se supo públicamente de la existencia del "Kiko", cuando familiares y amigos comenzaron a buscarlo en el sector. Primero fue un íntimo amigo de Barraza que llego en enero hasta la Municipalidad de Valdivia, dando cuenta ante las autoridades locales de la desaparición del "Kiko". Luego fueron los mismos padres del militante extraviado que visitaron la Municipalidad, quienes señalaron que habían perdido contacto con su hijo y que "presumían que pudo haber estado entre los componentes del campo guerrillero" $" 97$. Sin embargo, la prensa y las autoridades sostuvieron que la existencia del séptimo miembro de la escuela de guerrilla no era más que "una vulgar copucha"98.

Respecto al caso, Moreau opina que existen dos posibilidades: "la primera es que lo hayan agarrado los Boinas Negras cuando iban al campamento, que lo mataron y enterraron, y la otra es que el Kiko haya intentado salir, y haya muerto de frío"99. Finalmente, hasta el día de hoy el paradero del "Kiko" Barraza es desconocido, existiendo en torno a su figura una serie de misterios sin resolver.

Según uno de los principales dirigentes de la Organa, Rolando Calderón, el "Kiko" era un infiltrado de derecha que operó para desarticular la escuela de guerrilla de Chaihuín y la Organa ${ }^{100}$, por lo que su desaparición, según esta versión, no sería totalmente cierta. Moreau rechaza esta idea planteando que de haber sido así, Barraza habría aparecido condecorado en la dictadura ${ }^{101}$. Esta suposición de Calderón se debe a que Barraza era hijo de un destacado miembro de la Marina, Federico Barraza Pizarro, y a que antes de ser militante socialista fue Cadete en la Escuela Naval ${ }^{102}$. Finalmente, lo único cierto que hasta hoy nada se sabe del "Kiko" Barraza, siendo este episodio uno de los grandes temas que giran en torno a la escuela de guerrilla de Chaihuín.

\section{La reacción pública ante la escuela de guerrilla de Chaihuín}

El descubrimiento de una escuela de guerrilla a tan solo meses de la elección de 1970 causó una gran polémica política a nivel nacional. Y cómo no, si el partido que sostenía una de las candidaturas presidenciales mantenía a la vez, en secreto, un campamento de instrucción guerrillera en el sur del país. No podría pasar desapercibido que miembros del PS, partido al que pertenecía el candidato presidencial de la UP, desarrollara actividades de este tipo ad portas del periodo de campaña electoral.

Los primeros en reaccionar fueron los contrincantes de Allende: la derecha. Este episodio se presentó como una excelente oportunidad para desacreditar a la UP, validando el discurso sobre que un gobierno de izquierda, en el contexto de las guerrilleras latinoamericanas y la Revolución Cubana, no significaría más que desorden e ingobernabilidad. El periódico La Segunda, dependiente de la red de

95 Entrevista a Rigo Quezada, 22 de abril, 2017.

${ }^{96}$ Entrevista a Renato Moreau, 15 de mayo, 2017.

97 "Habría un joven desaparecido", El Correo de Valdivia, domingo 14 de febrero, 1971.

98 "Solo rumores pero nada concreto", El Correo de Valdivia, domingo 17 de febrero, 1971.

${ }_{99}$ Entrevista a Renato Moreau, 15 de mayo, 2017.

100 "Las memorias políticas de Rolando Calderón”, El Día de La Serena, 3 de mayo, 2010.

101 Entrevista a Renato Moreau, 15 de mayo, 2017.

102 Cristóbal Peña, "La misteriosa desaparición de un ex cadete naval en un campo guerrillero a meses de la elección de Allende", Santiago, Centro de Investigaciones Periodísticas (CIPER), 2007. 
medios de El Mercurio, no se demoró en difundir la existencia de un "foco guerrillero", intentando equiparar la experiencia de Chaihuín con la guerrilla del "Che" Guevara en Bolivia ${ }^{103}$. Ante esto, con ánimos de proteger la imagen de la UP, distintos dirigentes de la izquierda chilena salieron a pronunciarse sobre el tema.

La declaración que más llama la atención es la de Aniceto Rodríguez, quien, siendo Secretario General del PS, señaló que se preocupó de investigar los nombres de las personas implicadas en los hechos de Chaihuín, con el objetivo de asegurarse de que ninguno fuera militante socialista. "El Partido no tiene ninguna responsabilidad en los hechos", declaró ${ }^{104}$. Sus opiniones abrieron un intenso debate al interior del PS, lo cual era esperable si consideramos que en el partido convivían dos posturas claramente identificables: aquellos que ponían sus esfuerzos en la lucha electoral y rechazaban la vía armada; y aquellos que veían la necesidad de impulsar las resoluciones del Congreso de Chillán de prepararse para un enfrentamiento armado. De este modo, los socialistas que se pronunciaron con más ruido fueron los de Ñuble, quienes salieron a decir, públicamente, que los miembros de la escuela de guerrilla eran militantes del PS y que no hacían más que cumplir con la línea del partido:

Los camaradas Renato Moreau, Rigo Quezada Videla, Víctor Muñoz Espinoza, Sergio Torres Adelaida, Luis López y Jaime Briones Farías, militantes meritorios de nuestro partido, cuentan con el pleno respaldo y la más amplia solidaridad, pues su actitud es consecuente con nuestra línea política y con ella están abriendo el verdadero camino de la revolución chilena ${ }^{105}$.

En la misma línea del Secretario General de PS, el entonces Senador del PC, Volodia Teitelboim, declaró que como comunistas consideraban infructíferas las acciones emprendidas por los miembros de la escuela de Chaihuín, pues "la acción revolucionaria no puede realizarse con éxito sino a través del movimiento de masas" 106 .

Entretanto, la sociedad civil, al margen de las declaraciones de las dirigencias de los partidos políticas, también se hizo parte del episodio de la escuela de guerrilla de Chaihuín, y lo hizo de un modo bastante particular e inesperado. Por el contrario de lo que se podría pensar, la comunidad valdiviana mostró una actitud de respaldo más que de rechazo con los detenidos de la escuela.

Después de levantada la incomunicación, los presos de Chaihuín comenzaron a recibir constante visita de organizaciones que solidarizaban llevándoles comida y ropa ${ }^{107}$. Iban a entrevistarlos, a conversar con ellos, a darles ánimo, recuerda Quezada ${ }^{108}$. Nunca estuvieron solos mientras permanecieron cautivos en Valdivia. En el marco de distintas movilizaciones que exigían su libertad, Manuel Carpintero, para entonces militante de la JS en Valdivia y dirigente de la UTE, formó un Comité de Solidaridad con los presos $^{109}$, con el que realizó una serie de actividades de apoyo que resultaron tener una importante convocatoria de estudiantes de la UTE y la Universidad Austral. Incluso algunos medios locales, como la radio Camilo Henríquez, fueron considerados con los presos de Chaihuín y no los atacaron de forma grosera como El Mercurio ${ }^{110}$.

En julio de 1970, después de estar cautivos durante más de un mes, fueron trasladados a Osorno en forma de castigo por haber liderado, supuestamente, un motín en la cárcel de Valdivia ${ }^{111}$. Lo cierto es

103 “Actuó el ejército y policías: 2 detenidos por el foco guerrillero", La Segunda, 23 de mayo, 1970.

104 "Los guerrilleros no son socialistas", La Segunda, 26 de mayo, 1970.

105 "Los socialistas de Ñuble apoyan acción de los guerrilleros", La Segunda, 28 de mayo, 1970.

106 "Volodia Teitelboim se refiere a guerrillas", El Siglo, 23 de mayo de 1970.

107 Entrevista a Renato Moreau, 15 de mayo, 2017; Entrevista a Rigo Quezada, 22 de abril, 2017.

108 Entrevista a Rigo Quezada, 22 de abril, 2017.

${ }_{109}$ Este Comité de Solidaridad apareció públicamente en un texto firmado por Manuel Carpintero y Humberto Suazo. Ver "En defensa de los presos políticos”, Punto Final, N 108, martes 07 de julio de 1970.

110 Entrevista a Manuel Carpintero, 22 de abril, 2017.

111 "Guerrilleros trasladados a Osorno", El Correo de V aldivia, domingo 26 de julio, 1970. 
que el motín fue impulsado por los presos comunes del recinto penitenciario, y los presos de Chaihuín, debido probablemente a su mayor bagaje político, hicieron de voceros ante las autoridades de la penitenciaria ${ }^{112}$. De este episodio, recuerda Moreau, aprendieron que "en la cárcel nunca se gana".

Estando presos en Osorno recibieron la visita del candidato presidencial Salvador Allende, quien se encontraba en una gira por el sur en el marco de la campaña electoral ${ }^{113}$. Esto fue absolutamente inesperado, considerando los problemas que podía causarle a Allende visitar a militantes acusados de levantar un "foco guerrillero" en pleno periodo de elecciones. Sin embargo, la visita se llevó adelante, reuniéndose Allende con los presos de Chaihuín, más otros dirigentes socialistas. ${ }^{114}$.

\section{El después de la escuela de guerrilla de Chaihuín}

Es difícil saber con certeza qué paso con los participantes de la escuela de guerrilla después de cerrado el episodio. Sin embargo, a través de las distintas fuentes recopiladas se pueden deducir algunos elementos importantes.

En primer lugar, los presos de Chaihuín estuvieron privados de libertad hasta 1971, poco después de que Allende asumiera la presidencia de Chile. Según Moreau, no fueron liberados producto de un indulto como se tendería a pensar, sino que porque Allende desistió de las demandas que los presos tenían en su contra:

No nos indulta [Allende], pasaron dos cosas, nosotros estábamos presos por ley de seguridad interior del Estado, por subversión, y eso era una acusación que hacía el Ministerio del Interior, y además teníamos otra por robo de material de guerra, hurto de hallazgo (...) Nosotros estábamos procesados por la justicia militar, lo que hace Allende es desistirse de las demandas en nuestra contra. ${ }^{115}$

Los seis apresados por la escuela, así como el resto de los participantes que conformó el grupo anterior junto a Hernán Coloma, no pasaron a cumplir una única tarea como militantes tras ser parte de la experiencia de Chaihuín. Como vimos anteriormente, el objetivo de la Organa y sus escuelas no era formar cuadros político-militares, sino que preparar a militantes que cumplían distintas funcionas para estar listos ante la posibilidad de un enfrentamiento armado contra el ejército. Por ejemplo, Rigo Quezada, que antes de Chaihuín era dirigente estudiantil secundario, tras ser liberado volvió a sus labores de dirigente y a trabajar en la JS hasta exiliarse en Venezuela después del golpe de Estado. En ningún momento cumplió tareas militares en el PS o en otra estructura ${ }^{116}$. A modo de excepción, Moreau pasa a cumplir labores de índole militar, debido a que antes de Chaihuín ya desarrollaba tareas de ese tipo:

Los enviaban diferentes frentes a los compañeros (...) A ellos los asumen sus organizaciones de base. A mí sí me llama el Estado Mayor del ELN, y me plantea dos posibilidades, que eligiera entre ir al GAP, o ir a conformar, digamos, los primeros aparatos de seguridad para la UP, yo me voy a eso. Había que crearlo, en el GAP ya había compañeros con harta experiencia. ${ }^{117}$

Por lo tanto, tras terminar el proceso de formación militar, los militantes que participaron de la experiencia de Chaihuín volvieron a las tareas que realizaban antes de ser convocados por la Organa a las escuelas de guerrilla, con excepción de algunos que pasaron a cumplir labores de seguridad, como el caso

\footnotetext{
112 Entrevista a Renato Moreau, 15 de mayo, 2017

113 "Allende visitó a los presos", El Correo de Valdivia, miércoles 26 de agosto.

114 Fotografía del Archivo personal de Rigo Quezada. Ver anexos.

115 Entrevista a Renato Moreau, 15 de mayo, 2017.

116 Entrevista a Rigo Quezada, 22 de abril, 2017.

117 Entrevista a Renato Moreau, 15 de mayo, 2017.
} 
que mencionamos de Renato Moreau, y Jaime Sotelo, quien de ser instructor de la escuela de Guayacán pasó a formar parte del GAP.

En abril de 1970, a meses de desarticulada la escuela de guerrilla de Chaihuín, la Organa experimentó un proceso de fusión con en el ELN chileno ${ }^{118}$. Al respecto Hernán Coloma recuerda:

Me llamaron a reunión, a esa altura trabajaba con la JS. Ricardo Pincheira, muerto en combate en la moneda, citó a la dirección de la juventud, que éramos todos miembros de la Organa y nos planteó que a partir de ese día haríamos parte del Glorioso Ejército de Liberación Nacional, a lo cual me opuse, señalando que lo mínimo era preguntarme cuando se me proponía cambiar de organización, del PS al ELN. ${ }^{119}$

Lo mismo nos da a entender Moreau cuando nos señala:

Yo estaba preso, como en julio, nos llega la información, participamos en esa decisión de que la Organa se uniera al ELN y tomáramos el nombre del ELN, se tomó ese nombre porque era el ejército del Che (...) Entonces, ahí la Organa se funde y se toma lo que eran los Elenos ${ }^{120}$.

La fusión de ambas organizaciones fue posible gracias a los cambios que hubo en las estrategias de la Organa y el ELN en el contexto del triunfo de la Unidad Popular. La Organa, por su parte, en abril de 1970 concluyó que ante el triunfo de Allende correspondía defender el proceso frente a la violencia reaccionaria ${ }^{121}$, mientras que los militantes del ELN, en su calidad de militantes del PS, "pasaron a ejercer cargos de gobierno; debían preocuparse por la administración del país, por cautelar el orden público y avanzar hacia el socialismo siguiendo la estrategia diseñada por el Presidente"122.

De este modo, las concepciones sobre la lucha armada de la Organa y el ELN cambiaron, pero no con el objetivo de abandonar la violencia política, sino que para colaborar con el gobierno de la UP. Esto era esperable si consideramos que ambas organizaciones estaban compuestas por militantes del PS, aun más en el caso de la Organa que nunca declaró ser una organización independiente.

En el XXIII Congreso del PS realizado en La Serena en 1971, los sectores "pro vía armada" pasaron a ocupar un importante papel en la dirección del partido. En primer lugar, pasaron a formar parte del Comité Central del partido algunos de los principales referentes de la Organa y el ELN, lo cual da cuenta de la importancia de ambas entidades en el trabajo del PS entre 1970 y 1973. En el caso de los miembros de la Organa, pasaron a conformar el Comité Central del PS Rolando Calderón, Néstor Figueroa, y el participante de la escuela de Chaihuín, Hernán Coloma ${ }^{123}$. Respecto a los elenos se integraron al Comité Central Arnoldo Camú y Exequiel Ponce. Junto con estos cambios en la organización del partido, fue escogido Secretario General el entonces senador Carlos Altamirano, quien fuera un conocido dirigente por sus posturas más radicales respecto a la vía democrática al socialismo ${ }^{124}$.

Por otro lado, otra definición fundamental del XXIII Congreso de 1971 fue la creación de una Comisión de Defensa de la que dependieron un Aparato Militar y una Estructura de Inteligencia, las que estuvieron a cargo de Exequiel Ponce y Arnoldo Camú ${ }^{125}$. Ambas entidades cumplieron labores de colaboración con el GAP hasta 1973126. Finalmente, según el historiador Patricio Quiroga, en este último

\footnotetext{
118 Quiroga, op. cit., 45.

119 Entrevista a Hernán Coloma, 9 de septiembre, 2017.

${ }^{120}$ Entrevista a Renato Moreau, 15 de mayo, 2017.

121 Quiroga, op. cit., 44.

122 Cristián Pérez, "El ejército del Che...” op. cit., 250.

123 Jobet, op. Cit., 171.

124 Ibid, 171.

125 Quiroga, op. cit., 70.

126 Ibid, 75.
} 
congreso general del PS antes del golpe de Estado de 1973, la fusión ELN/Organa se constituyó como la dirección del partido, "dado que ejercía el control orgánico, mantenía relaciones internacionales, disponía de líderes y tenía el aval de la experiencia boliviana. Fue un polo de atracción que fascinó al PS y que controló a más de la mitad de los 47 miembros del Comité Central"127.

En síntesis, la Organa fue una organización que operó durante toda su existencia sin contradecir las posiciones del PS, lo que permitió que en tres años de desarrollo llegará a ocupar un importante puesto en la dirección del partido. Sus acciones, incluida la escuela de guerrilla de Chaihuín, fueron pensadas y realizadas en la línea de las definiciones del emblemático Congreso de Chillán de 1967, por lo que es importante comprender que, al estudiar la historia de este grupo, se está estudiando, en estricto rigor, la historia del PS chileno.

\section{Conclusiones}

Los procesos de leninización y guevarización experimentados por el socialismo chileno generaron las condiciones para que en 1968 se forme el grupo conocido como la Organa. Según lo investigado, esta organización fue una estructura clandestina interna del PS que se propuso materializar las tesis del Congreso de Chillán de 1967, lo que implicaba, según sus análisis, preparar las condiciones para un enfrentamiento armado que se consideraba inevitable. Por esta razón, su trabajo se centró, según lo estudiado hasta ahora, en instruir a grupos de militantes en el uso de armas y en el conocimiento de estrategias de enfrentamiento militar. Es importante tener en cuenta que la Organa no desarrolló, según su visión, otra estrategia que no fuese la zanjada por el PS en Chillán, lo que la diferencia de la otra importante organización armada de raigambre socialista: los elenos chilenos.

Teniendo en cuenta la visión de la Organa sobre el proceso revolucionario, se plantea que la escuela de guerrilla de Chaihuín constituyó uno de sus principales esfuerzos por cristalizar su estrategia de preparación militar. En la experiencia no participaron únicamente cuadros destinados para la lucha armada, sino que también dirigentes sociales (como el caso del dirigente estudiantil Rigo Quezada), lo cual dice relación con el objetivo de la Organa de formar a la militancia para un enfrentamiento armado que se presentaría tarde o temprano en cualquier escenario y no cuadros dedicados únicamente a la lucha armada o a la constitución de focos guerrilleros. Por este motivo, si bien se plantea que el nacimiento de la Organa estuvo motivado por la guevarización del PS, esto no quiere decir que adoptó al guevarismo como principio rector de su estrategia. Es más, podría concluirse, aun tentativamente, que la Organa no desarrolló mayores definiciones propias sobre cómo desarrollar el proceso revolucionario en Chile, sino que más bien intentó hacerse cargo de lo que el mismo PS definió como "inevitabilidad de la violencia revolucionaria", para posteriormente continuar participando del proceso del gobierno de la UP liderado por Allende.

Por otro lado, la escuela de guerrilla de Chauín se desarrolló en un momento de alta complejidad para el PS y la izquierda: los meses previos a la campaña electoral de 1970. Los sectores conservadores no dudaron en utilizar el episodio para deslegitimar al proyecto que se configuraba en torno a Allende, lo cual explica que el mismo Secretario General del PS haya querido desmarcar al partido de lo ocurrido. Sin embargo, a partir de lo estudiado se concluye que la Organa no tuvo por objetivo interrumpir ni reemplazar de ningún modo el proceso de lucha electoral que se venía fraguando, sino que, como se ha insistido, propuso preparar las condiciones para enfrentarse a la reacción armada inevitable de la derecha y el empresariado. Ahora bien, es sabido que en el PS no existió un acuerdo sobre cómo abordar el tema de la violencia revolucionaria, lo cual se manifestó en que ante el episodio de Chaihuín existiesen posiciones contradictorias entre los socialistas. Es más, que la Organa haya proclamado actuar en la línea de las definiciones partidarias mientras la dirección del partido desaprobó sus operaciones es expresión

${ }^{127} \mathrm{Ibid}, 72$. 
de las diferentes visiones que hubo en el PS sobre la lucha armada. Finalmente, no se constata que el incidente haya tenido un impacto negativo significativo que pudiese haber mermado el resultado electoral de la UP.

Respecto a los objetivos de la escuela, es difícil saber con exactitud si se cumplieron. Aun cuando algunos participantes de la escuela de Chaihuín y otros miembros de la Organa pasaron a trabajar en los dispositivos de seguridad de la UP, no es posible, hasta ahora, saber si su preparación fue adquirida tras su experiencia en la Organa o en otras estructuras, dado que miembros de la Organa fueron también integrantes de los elenos (como en el caso de Renato Moreau). A partir de este trabajo, es fundamental continuar investigando sobre la relación Organa/ELN para profundizar el conocimiento que se tiene sobre la historia de la Organa, sobre todo porque la fusión de ambas estructuras les permitió ocupar un importante lugar en la dirección del PS tras el congreso partidario de 1971. De este modo, queda abierta la pregunta sobre el papel que jugó la Organa en la formación de una alianza con los elenos y el rol que cumplió, teniendo miembros en la dirección del partido, durante el gobierno de la UP y los años posterior al golpe de Estado.

Anexos

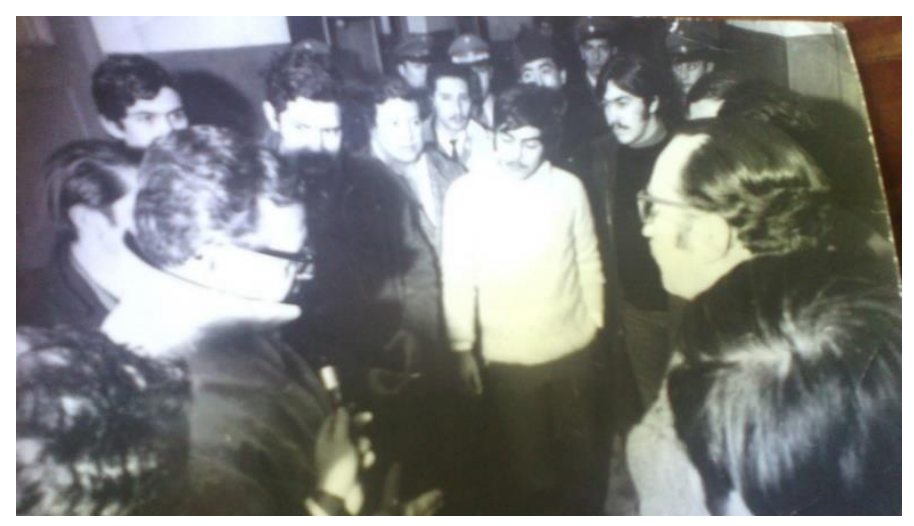

Allende visita a los presos de Chaihuín en la cárcel de Osorno. En la foto: Salvador Allende (lado izquierdo de la foto); Renato Moreau (a su derecha frente a él mirándolo); Rigo Quezada (al lado derecho de Moreau). Fuente: Archivo personal de Rigo Quezada.

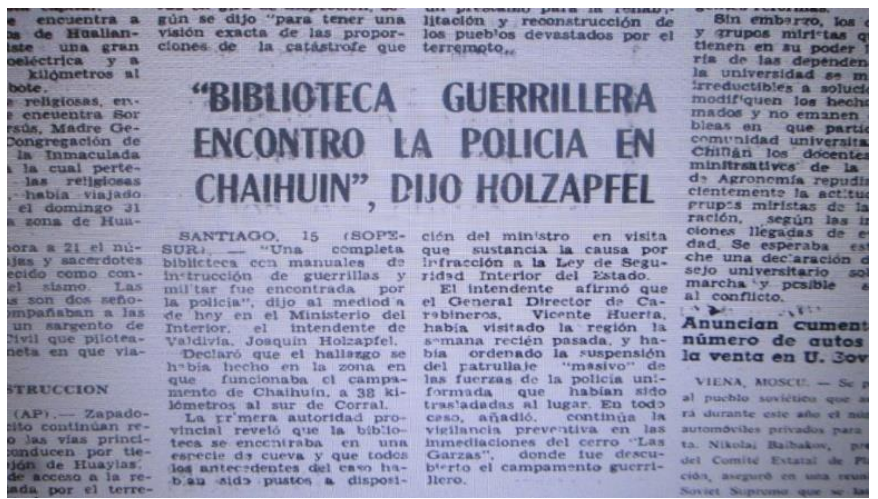

Noticia en el periódico La Prensa de Osorno el 27 de junio de 1970. El entonces Intendente de Valdivia, Joaquín Holzapfel Anwandter, anuncia el descubrimiento de una "biblioteca guerrillera". 


\section{Bibliografía y fuentes}

\section{Libros y artículos}

Arrate, J., y Rojas E., Memorias de la izquierda chilena: Tomo I (1859-1970), Santiago, Ediciones B, 2003.

Azócar, Juan, Lorca: Vida de un socialista ejemplar, Santiago, Ediciones Radio Universidad de Chile, 2015.

Casanueva, F., y Fernández, M., El Partido Socialista y la lucha de clases en Chile, Santiago, Editorial Quimantú, 1973.

Chelen, Alejandro, Trayectoria del socialismo (apuntes para una historia crítica de socialismo chileno), Buenos Aires, Editorial Astral, 1996.

Fermandois, Joaquín, La revolución inconclusa: La izquierda chilena y el gobierno de la Unidad Popular, Santiago, Centro de Estudios Públicos, 2014.

Goicovic, I., Pinto, J., Lozoya, I., y Pérez, C. (compiladores), Escrita con sangre: Historia de la violencia en América Latina: Siglos XIX y XX, Santiago, Ceibo Ediciones, 2013.

Holzapfel, Joaquín, Calle Calle, Valdivia, Ediciones de la Universidad Austral, 2007.

Jobet, Julio Cesar, El Partido Socialista de Chile (Tomo II), Santiago, Editorial Prensa Latinoamericana, 1971. Moulian, Tomás, Democracia y socialismo en Chile, Santiago, FLACSO, 1983.

Palieraki, Eugenia, ¡La revolución ya viene! El MIR chileno en los años sesenta, Santiago, LOM Ediciones, 2014. Pérez, Cristián, "El ejército del Che y los chilenos que continuaron su lucha", en Estudios Públicos, n 89, Santiago, 2003.

Pérez, Cristián, "Guerrilla rural en Chile: La batalla del fundo San Miguel”, en Estudios Públicos, n 78, 2000.

Peña, Cristóbal, "La misteriosa muerte de un ex cadete naval en un campo guerrillero a meses de la elección de Allende", en CIPER, Santiago, 2007. Disponible en: http://ciperchile.cl/2007/11/12/el-excadete-nava-que-desaparecio-misteriosamente-en-un-campamento-guerrillero-antes-de-allende/.

Quiroga, Patricio, Compañeros. El GAP: la escolta de Allende, Santiago, Editorial Aguilar, 2001.

Valdés, Pedro, El compromiso internacionalista: El Ejército de Liberación Nacional. Los elenos chilenos, 1966-1971. Formación e identidad, Santiago, LOM Ediciones, 2018.

Waiss, Oscar, Nacionalismo y socialismo en América Latina, Buenos Aires, Ediciones Iguazú, 1961.

\section{Periódicos y revistas}

La Segunda, disponible en el Archivo de la Biblioteca Nacional.

La Prensa de Osorno, disponible en el Archivo de la Biblioteca Nacional.

El Correo de Valdivia, disponible en el Archivo de la Municipalidad de Valdivia.

El Siglo, disponible en el Archivo de la Biblioteca Nacional.

Revista Punto Final, disponible en línea en http://www.puntofinal.cl

\section{Entrevistas}

Entrevista a Renato Moreau, 15 de mayo de 2017.

Entrevista a Rigo Quezada, 15 de mayo de 2017.

Entrevista a Hernán Coloma, 9 de septiembre de 2017.

Entrevista a Manuel Carpintero, 22 de abril de 2017.

Entrevista a Eduardo Olivares, 20 de junio de 2017.

\section{Documentos de la época}

Boletín N² 2 del Comité Ejecutivo del PSP, 1955, en http:/ /www.socialismo-chileno.org/bcc/bcc.html. Informe secreto al XX Congreso del PCUS, Nikita Khrushchev, 1946, en https://www.marxists.org/espanol/khrushchev/1956/febrero25.htm.

Resolución Política del Congreso de Unidad, 1957, en http://www.socialismochileno.org/adonis/caja2/2E/res_politica_congreso_unidad_1957_a.pdf. 